\title{
Remarkable effect of alkynyl substituents on the fluorescence properties of a BN-phenanthrene
}

\author{
Alberto Abengózar, David Sucunza, Patricia García-García ${ }^{*}$ and Juan J. Vaquero*
}

\author{
Full Research Paper \\ Address: \\ Departamento de Química Orgánica y Química Inorgánica, Instituto \\ de Investigación Química "Andrés M. del Río" (IQAR), Universidad de \\ Alcalá, 28871-Alcalá de Henares, Madrid, Spain \\ Email: \\ Patricia García-García* - patricia.garciagarci@uah.es; \\ Juan J. Vaquero* - juanjose.vaquero@uah.es \\ * Corresponding author \\ Keywords: \\ alkyne; BN-phenanthrene; cross-coupling; fluorescence; heterocycles
}

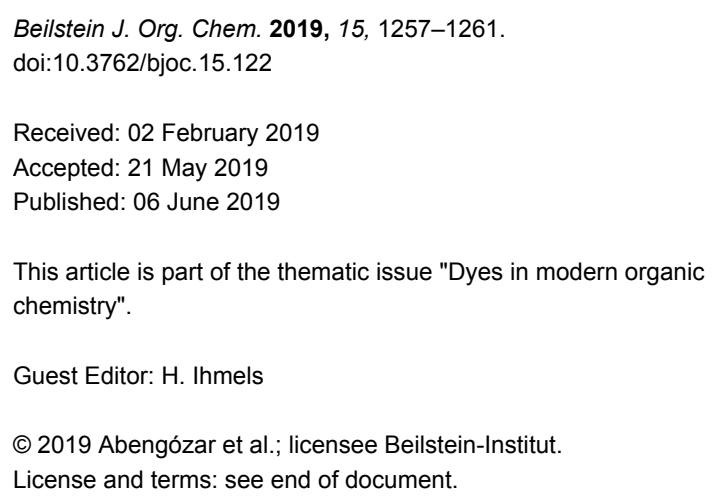

\begin{abstract}
A series of BN-phenanthrenes with substituents of a diverse nature have been synthesized by palladium-catalyzed cross-coupling reactions of a common chloro-substituted precursor, which was made from readily available materials in only four steps. Evaluation of the photophysical properties of the prepared compounds unveiled an impressive effect of the presence of alkynyl substituents on the fluorescence quantum yield, which improved from 0.01 in the parent compound to up to 0.65 in derivatives containing a triple bond.
\end{abstract}

\section{Introduction}

$\mathrm{BN}$-polycyclic aromatic hydrocarbons (BN-PAHs) have received increasing interest over the past few years [1-5], particularly in the field of materials science [6]. The presence of a polarized B-N bond induces significant changes in the photophysical properties of these compounds when compared to their $\mathrm{PAH}$ analogues containing only non-polar $\mathrm{C}=\mathrm{C}$ bonds. This fact opens up new opportunities for creating improved optoelectronic devices [7-15].

The introduction of substituents is known to have a substantial influence on the photophysical properties of PAHs. However, although some particular examples of the impact of substituents on the behaviour of BN-PAHs have been reported [16-21], systematic studies are not usually performed, probably due to the difficulties associated with their synthesis and the lack of general methods for their functionalization [22].

We have recently designed an efficient synthesis for one of the simplest BN-PAHs, namely BN-phenanthrene 1a [23]. We are interested in evaluating the reactivity [24] and properties of 1a in greater detail as this could provide valuable information that leads to a better understanding of the behaviour of 
BN-aromatics. Interestingly, 1a turned out to be weakly fluorescent [23], in contrast to other BN-phenanthrene isomers described previously $[25,26]$. The presence of aryl or amino substituents at $\mathrm{C} 1$, which can be introduced via bromination and subsequent palladium-catalyzed cross coupling, does not have a significant impact on the fluorescence of these compounds (Figure 1) [23]. In order to gain a deeper understanding of the photophysical properties of the $\mathrm{BN}$-phenanthrene core, we decided to evaluate the influence of substituents located in other positions. We were particularly interested in the effect of alkynyl substituents, as their presence in PAHs is known to alter the fluorescence properties thereof markedly [27-29]. In this regard, we have recently described a methodology for the synthesis of a chloro-substituted BN-benzo[c]phenanthrene and its subsequent derivatization via palladium-catalyzed cross-coupling reactions [30], and we envisioned that this reaction could be used to prepare $\mathrm{C} 7$ substituted $\mathrm{BN}$-phenanthrenes (Figure 1).

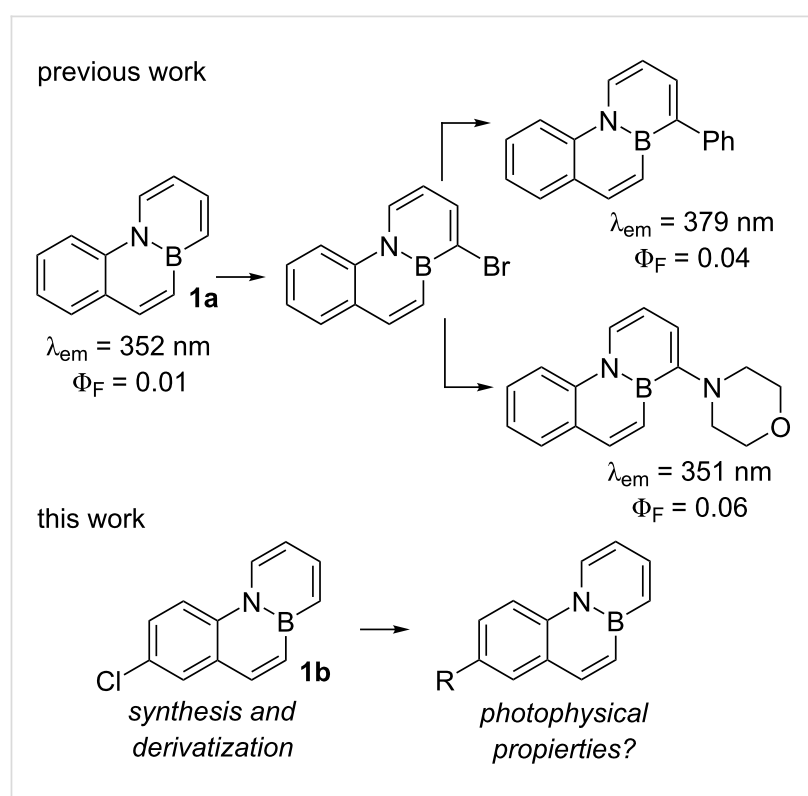

Figure 1: BN-phenanthrene 1a and synthesis of substituted derivatives proposed in this work.

Herein we report the synthesis of chloro-substituted $\mathrm{BN}$-phenanthrene $\mathbf{1 b}$, its derivatization via palladium-catalyzed cross-coupling reactions and the significant effect of the substituents on the fluorescence properties of the compounds prepared.

\section{Results and Discussion}

Our first aim was to synthesise the Cl-substituted BN-phenanthrene 1b (Scheme 1), following a synthetic sequence analogous to that described previously by us for preparation of the parent BN-phenanthrene 1a [23]. Thus, an initial Buchwald-Hartwig amination between 2-bromo-5-chlorostyrene and 3-butenylamine was the initial step. This coupling was performed at $70{ }^{\circ} \mathrm{C}$, as a higher yield was obtained at this temperature $\left(71 \%\right.$ at $80{ }^{\circ} \mathrm{C}, 24 \mathrm{~h}$ vs $82 \%$ at $\left.70{ }^{\circ} \mathrm{C}, 48 \mathrm{~h}\right)$. Substrate 2 was then cyclized with vinyl trifluoroborate. The optimal conditions to obtain 3 were found to be heating at $110^{\circ} \mathrm{C}$ for $72 \mathrm{~h}$. Lower temperatures and/or shorter times led to incomplete conversions in the borylative cyclization of $\mathbf{2}$. Ring-closing metathesis of $\mathbf{3}$ proceeded efficiently in the presence of $10 \mathrm{~mol} \%$ of the second-generation Grubbs catalyst to yield dihydro-BNphenanthrene 4 , which was oxidized to $\mathbf{1 b}$ under the conditions previously optimized for the synthesis of the parent BN-phenanthrene 1a [23].

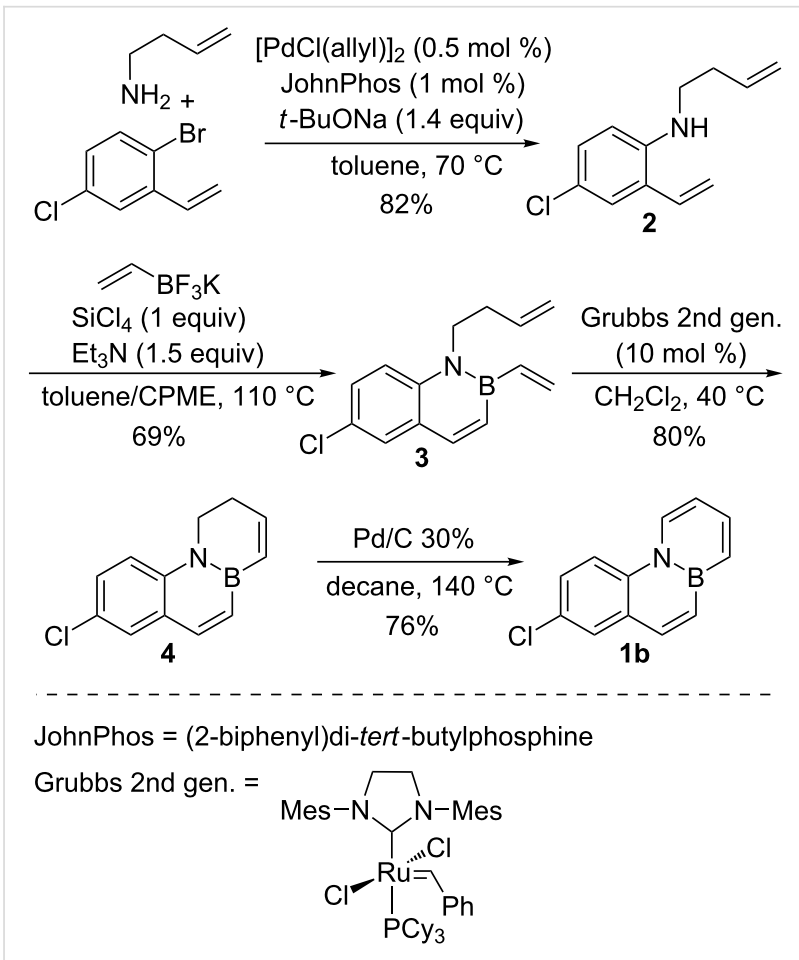

Scheme 1: Synthesis of Cl-substituted BN-phenanthrene $\mathbf{1 b}$.

Next, we explored the preparation of various substituted $\mathrm{BN}$-phenanthrenes by means of palladium-catalyzed cross-coupling reactions of $\mathbf{1 b}$, under conditions optimized for a related BN-benzo[c]phenanthrene [30]. Gratifyingly, Suzuki coupling and Buchwald-Hartwig amination yielded the corresponding aryl- and amino-substituted BN-phenanthrenes $\mathbf{1 c}$ and $\mathbf{1 d}$ in good yields (Scheme 2).

Moreover, Sonogashira couplings efficiently proceed to provide alkynyl-substituted BN-phenanthrenes 1e and $\mathbf{1 f}$ in excellent yields (Scheme 3). These results confirm the value of palladium-catalyzed cross-coupling reactions of chloro-substituted $\mathrm{BN}$-arenes as a useful tool for the preparation of derivatives functionalized with a range of substituents of a different nature. 


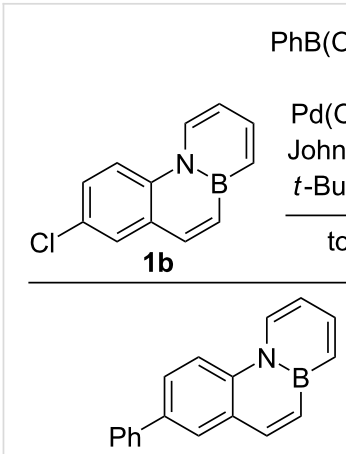

1c, $50 \%$
$\mathrm{PhB}(\mathrm{OH})_{2}$ or morpholine

( 2 equiv)

$\mathrm{Pd}(\mathrm{OAc})_{2}(10 \mathrm{~mol} \%)$

JohnPhos (20 mol \%)

$t$-BuONa ( 1.5 equiv)

toluene, $110{ }^{\circ} \mathrm{C}$

1c,d

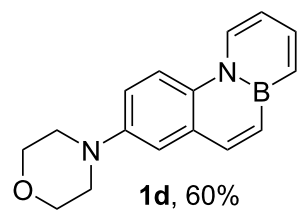

Scheme 2: Palladium-catalyzed cross-couplings of $\mathrm{Cl}$-substituted BN-phenanthrene 1b.<smiles>Clc1ccc2c(c1)C=CB1C=CC=CN12</smiles>
$1 b$<smiles>O=S(=O)(O)c1cc2c(cc1C#CC1=CCCCC1)N1C=CC=CB1C=C2</smiles>

Scheme 3: Pd-catalyzed Sonogashira reactions of Cl-substituted BN-phenanthrene 1b.

\section{$\mathrm{R}=(1.3$ equiv)}

$\mathrm{PdCl}_{2}(\overline{\mathrm{MeCN}})_{2}(5 \mathrm{~mol} \%)$

XPhos (15 mol \%)

$\mathrm{Cs}_{2} \mathrm{CO}_{3}$ (2.5 equiv)

$\mathrm{MeCN}, 100^{\circ} \mathrm{C}$

le,f

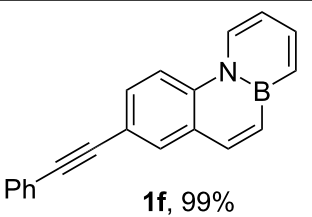

1f, $99 \%$
Once we had developed a useful method for the synthesis of the functionalized BN-phenanthrenes 1, we focussed on our initial goal of evaluating the influence of different substituents on the photophysical properties thereof. The absorption and emission spectra of the parent BN-phenanthrene 1a and the derivatives prepared in this work are shown in Figure 2. 1-(Phenylethynyl)-
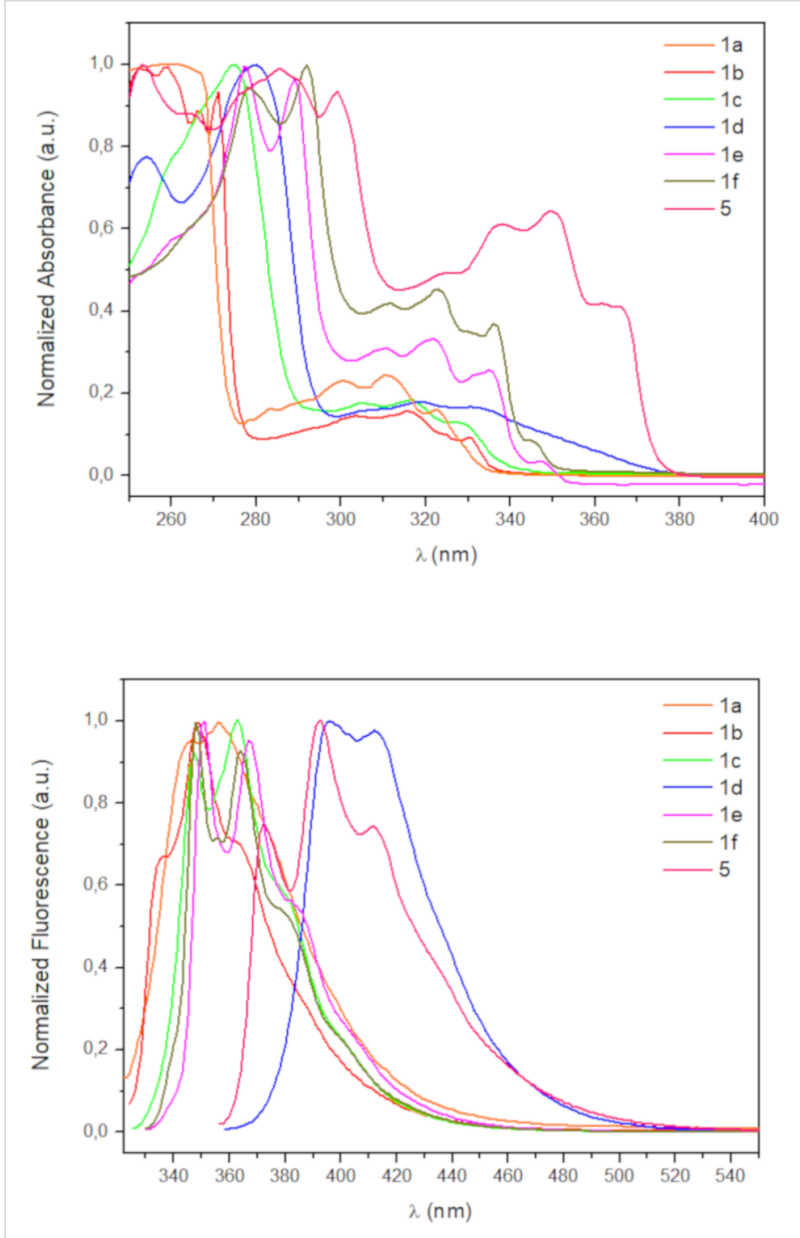

Figure 2: UV-vis absorption (top) and emission (bottom) spectra for BN-phenanthrenes 1 and $\mathbf{5}$ in cyclohexane $(\approx 0.02 \mathrm{mM})$.

4a-aza-10a-boraphenanthrene (5), which was previously prepared in our group by bromination of $\mathbf{1 a}$ and subsequent coupling [23], was also included in this comparative study. The absorption and emission data for these compounds are summarized in Table 1, and a picture of their solutions under UV irradiation are shown in Figure 3.

Table 1: UV-vis and fluorescence data for BN-phenanthrenes $\mathbf{1 a}-\mathbf{f}$ and $\mathbf{5} .^{\mathrm{a}}$

\begin{tabular}{lllll} 
Compound & $\varepsilon\left(\mathrm{M}^{-1} \mathrm{~cm}^{-1}\right)$ & $\lambda_{\text {abs } \max }(\mathrm{nm})$ & $\lambda_{\text {em }}(\mathrm{nm})$ & $\Phi_{\mathrm{f}}^{\mathrm{b}}$ \\
\hline 1a & 5488 & 310 & 356 & 0.01 \\
1b & 7715 & 316 & 349 & 0.03 \\
1c & 7482 & 316 & 363 & 0.17 \\
1d & 4331 & 319 & 395 & 0.19 \\
1e & 18283 & 322 & 351 & 0.44 \\
1f & 19392 & 323 & 348 & 0.65 \\
$\mathbf{5}$ & 15851 & 350 & 392 & 0.45 \\
\hline
\end{tabular}

aAll experiments were performed in cyclohexane solution $(\approx 0.01-0.02 \mathrm{mM})$. The excitation wavelength match the absorption maxima for each compound. ${ }^{b} Q u a n t u m$ yields reported relative to 9,10 -diphenylanthracene $\left(\Phi_{f}=0.93\right)$. 


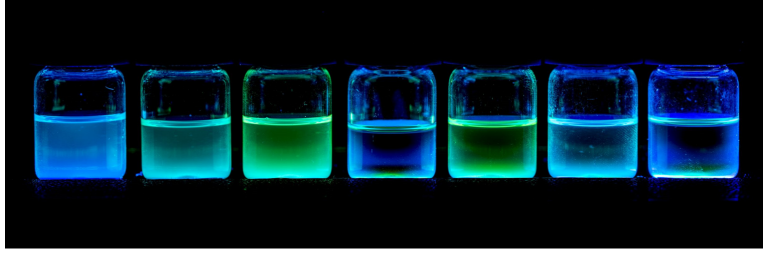

Figure 3: Solutions of 1a-f and $\mathbf{5}$ (from left to right) under UV irradiation.

The emission maxima were not significantly affected by the presence of substituents, except for 7-amino substituted BN-phenanthrene 1d and 1-alkynyl substituted BN-phenanthrene 5, whose emission maxima are slightly red-shifted (395 and $392 \mathrm{~nm}$ vs $356 \mathrm{~nm}$ for unsubstituted 1a). In contrast, 7-alkynyl-substituted BN-phenanthrenes 1e and 1f show emission maxima analogous to that of the parent BN-phenanthrene 1a. With regard to the fluorescence quantum yield, phenyl and morpholine substituents at $\mathrm{C} 7$ (1c and 1d) provide a significant increase when compared to the parent compound ( 0.17 and 0.19 vs 0.01 ). This enhancement is higher than that observed when these same substituents are located at C1 (see Figure 1) [23]. More interestingly, the presence of alkynyl substituents at $\mathrm{C} 7$ gives rise to a marked increase in the fluorescence quantum yield (0.44 and 0.65$)$, particularly when the triple bond is bonded to a phenyl ring (1f). A similar increase $\left(\Phi_{\mathrm{f}}=0.45\right)$ is observed when the alkynyl group is attached to C1 (5), thus indicating that the positive influence of the triple bond on the fluorescence quantum yield of BN-phenanthrene seems to be a general effect, irrespective of its position. It should be noted that the introduction of ethynyl groups into the all-carbon phenanthrene skeleton results in a slight increase in the fluorescence quantum yields compared to that of phenanthrene [27]. However, the effect observed here for $\mathrm{BN}$-phenanthrenes is much more pronounced [31]. We have also evaluated the emission of $\mathbf{1 f}$ in different solvents. The emission maxima are almost unaffected by the nature of the solvent [32], whereas the fluorescence quantum yield decreases in more polar solvents (0.29 in $\mathrm{CH}_{2} \mathrm{Cl}_{2}, 0.19$ in THF, 0.39 in 1,4-dioxane, 0.26 in $\mathrm{MeCN})$

\section{Conclusion}

We have successfully prepared a chloro-substituted BN-phenanthrene derivative that serves as a useful intermediate for the synthesis of a range of $\mathrm{BN}$-phenanthrenes substituted with groups of diverse nature at C-7. This efficient post-functionalization methodology allows the influence of substituents on the photophysical properties of the BN-phenanthrene core to be studied. Substituted derivatives show an improved quantum yield with respect to the parent BN-phenanthrene, an effect that is particularly noteworthy for alkynyl substituents. A
$\mathrm{BN}-$ phenanthrene bearing the triple bond at C-1 shows a similar increase in the quantum yield, thus suggesting that the influence of the alkynyl substituent is not limited to a particular position. We consider that this discovery may have important implications in the discovery of novel $\mathrm{BN}$-arenes with improved properties. Further studies into the effect of alkynyl substituents on the fluorescence of $\mathrm{BN}$-arenes are currently ongoing in our laboratories.

\section{Supporting Information}

\section{Supporting Information File 1}

Experimental details and NMR spectra for all new compounds.

[https://www.beilstein-journals.org/bjoc/content/ supplementary/1860-5397-15-122-S1.pdf]

\section{Acknowledgements}

We are grateful to the Ministerio de Economía y Competitividad (MINECO), AEI and FEDER (project CTQ2017-85263R, FPU predoctoral grant for A.A. and "Ramón y Cajal" contract for P.G.G.), Instituto de Salud Carlos III (FEDER funds, ISCIII RETIC REDINREN RD16/0009/0015), and University of Alcalá (project CCGP2017-EXP012) for financial support.

\section{ORCID ${ }^{\circledR}$ iDs}

David Sucunza - https://orcid.org/0000-0002-3307-4204

Patricia García-García - https://orcid.org/0000-0003-3671-5828

Juan J. Vaquero - https://orcid.org/0000-0002-3820-9673

\section{References}

1. Wang, X.-Y.; Wang, J.-Y.; Pei, J. Chem. - Eur. J. 2015, 21 , 3528-3539. doi:10.1002/chem.201405627

2. Campbell, P. G.; Marwitz, A. J. V.; Liu, S.-Y. Angew. Chem. 2012, 124, 6178-6197. doi:10.1002/ange.201200063

Campbell, P. G.; Marwitz, A. J. V.; Liu, S.-Y. Angew. Chem., Int. Ed. 2012, 51, 6074-6092. doi:10.1002/anie.201200063

3. Bosdet, M. J. D.; Piers, W. E. Can. J. Chem. 2009, 87, 8-29. doi:10.1139/v08-110

4. Giustra, Z. X.; Liu, S.-Y. J. Am. Chem. Soc. 2018, 140, 1184-1194 doi:10.1021/jacs.7b09446

5. Bélanger-Chabot, G.; Braunschweig, H.; Roy, D. K. Eur. J. Inorg. Chem. 2017, 4353-4368. doi:10.1002/ejic.201700562

6. Wang, J.-Y.; Pei, J. Chin. Chem. Lett. 2016, 27, 1139-1146. doi:10.1016/j.cclet.2016.06.014

7. Nakatsuka, S.; Yasuda, N.; Hatakeyama, T. J. Am. Chem. Soc. 2018, 140, 13562-13565. doi:10.1021/jacs.8b08197

8. Zhang, W.; Zhang, F.; Tang, R.; Fu, Y.; Wang, X.; Zhuang, X.; He, G.; Feng, X. Org. Lett. 2016, 18, 3618-3621. doi:10.1021/acs.orglett.6b01659

9. Li, G.; Zhao, Y.; Li, J.; Cao, J.; Zhu, J.; Sun, X. W.; Zhang, Q. J. Org. Chem. 2015, 80, 196-203. doi:10.1021/j0502296z 
10. Hashimoto, S.; Ikuta, T.; Shiren, K.; Nakatsuka, S.; Ni, J.; Nakamura, M.; Hatakeyama, T. Chem. Mater. 2014, 26, 6265-6271. doi:10.1021/cm503102d

11. Wang, X.; Zhang, F.; Liu, J.; Tang, R.; Fu, Y.; Wu, D.; Xu, Q.; Zhuang, X.; He, G.; Feng, X. Org. Lett. 2013, 15, 5714-5717. doi:10.1021/ol402745r

12. Wang, X.-Y.; Zhuang, F.-D.; Wang, J.-Y.; Pei, J. Chem. Commun. 2015, 51, 17532-17535. doi:10.1039/c5cc06927k

13. Wang, X.-Y.; Zhuang, F.-D.; Wang, R.-B.; Wang, X.-C.; Cao, X.-Y.; Wang, J.-Y.; Pei, J. J. Am. Chem. Soc. 2014, 136, 3764-3767. doi:10.1021/ja500117z

14. Wang, X.-Y.; Zhuang, F.-D.; Zhou, X.; Yang, D.-C.; Wang, J.-Y.; Pei, J. J. Mater. Chem. C 2014, 2, 8152-8161. doi:10.1039/c4tc01369g

15. Wang, X.-Y.; Lin, H.-R.; Lei, T.; Yang, D.-C.; Zhuang, F.-D.; Wang, J.-Y.; Yuan, S.-C.; Pei, J. Angew. Chem. 2013, 125, 3199-3202. doi:10.1002/ange.201209706 Wang, X.-Y.; Lin, H.-R.; Lei, T.; Yang, D.-C.; Zhuang, F.-D.; Wang, J.-Y.; Yuan, S.-C.; Pei, J. Angew. Chem., Int. Ed. 2013, 52, 3117-3120. doi:10.1002/anie.201209706

16. Zhang, W.; Fu, Y.; Qiang, P.; Hunger, J.; Bi, S.; Zhang, W.; Zhang, F. Org. Biomol. Chem. 2017, 15, 7106-7111. doi:10.1039/c7ob01679d

17. Huang, H.; Pan, Z.; Cui, C. Chem. Commun. 2016, 52, 4227-4230. doi:10.1039/c6cc00161k

18. Wang, X.-Y.; Yang, D.-C.; Zhuang, F.-D.; Liu, J.-J.; Wang, J.-Y.; Pei, J. Chem. - Eur. J. 2015, 21, 8867-8873. doi:10.1002/chem.201501161

19. Liu, X.; Wu, P.; Li, J.; Cui, C. J. Org. Chem. 2015, 80, 3737-3744. doi:10.1021/j05029437

20. Sun, F.; Lv, L.; Huang, M.; Zhou, Z.; Fang, X. Org. Lett. 2014, 16, 5024-5027. doi:10.1021/ol502339h

21. Bosdet, M. J. D.; Piers, W. E.; Sorensen, T. S.; Parvez, M. Angew. Chem. 2007, 119, 5028-5031. doi:10.1002/ange.200700591 Bosdet, M. J. D.; Piers, W. E.; Sorensen, T. S.; Parvez, M. Angew. Chem., Int. Ed. 2007, 46, 4940-4943. doi:10.1002/anie.200700591

22. Morgan, M. M.; Piers, W. E. Dalton Trans. 2016, 45, 5920-5924. doi:10.1039/c5dt03991f

23. Abengózar, A.; García-García, P.; Sucunza, D.; Frutos, L. M.; Castaño, O.; Sampedro, D.; Pérez-Redondo, A.; Vaquero, J. J. Org. Lett. 2017, 19, 3458-3461. doi:10.1021/acs.orglett.7b01435

24. Abengózar, A.; Fernández-González, M. A.; Sucunza, D.; Frutos, L. M.; Salgado, A.; García-García, P.; Vaquero, J. J. Org. Lett. 2018, 20 , 4902-4906. doi:10.1021/acs.orglett.8b02040

25. Bosdet, M. J. D.; Jaska, C. A.; Piers, W. E.; Sorensen, T. S.; Parvez, M. Org. Lett. 2007, 9, 1395-1398. doi:10.1021/ol070328y

26. Lu, J.-S.; Ko, S.-B.; Walters, N. R.; Kang, Y.; Sauriol, F.; Wang, S. Angew. Chem. 2013, 125, 4642-4646. doi:10.1002/ange.201300873 Lu, J.-S.; Ko, S.-B.; Walters, N. R.; Kang, Y.; Sauriol, F.; Wang, S. Angew. Chem., Int. Ed. 2013, 52, 4544-4548. doi:10.1002/anie.201300873

27. Hakoda, Y.; Aoyagi, M.; Irisawa, K.-i.; Kato, S.-i.; Nakamura, Y.; Yamaji, M. Photochem. Photobiol. Sci. 2016, 15, 1586-1593. doi:10.1039/c6pp00291a

28. Yamaji, M.; Maeda, H.; Nanai, Y.; Mizuno, K. Chem. Phys. Lett. 2012, 536, 72-76. doi:10.1016/j.cplett.2012.03.108

29. Maeda, H.; Maeda, T.; Mizuno, K.; Fujimoto, K.; Shimizu, H.; Inouye, M. Chem. - Eur. J. 2006, 12, 824-831. doi:10.1002/chem.200500638

30. Abengózar, A.; García-García, P.; Sucunza, D.; Pérez-Redondo, A.; Vaquero, J. J. Chem. Commun. 2018, 54, 2467-2470. doi:10.1039/c7cc09264d
31. Abengózar, A.; García-García, P.; Sucunza, D.; Sampedro, D. Pérez-Redondo, A.; Vaquero, J. J. Org. Lett. 2019, 21, 2550-2554. doi:10.1021/acs.orglett.9b00448

32. See Supporting Information File 1 for details.

\section{License and Terms}

This is an Open Access article under the terms of the Creative Commons Attribution License (http://creativecommons.org/licenses/by/4.0). Please note that the reuse, redistribution and reproduction in particular requires that the authors and source are credited.

The license is subject to the Beilstein Journal of Organic Chemistry terms and conditions:

(https://www.beilstein-journals.org/bjoc)

The definitive version of this article is the electronic one which can be found at: doi:10.3762/bjoc. 15.122 